
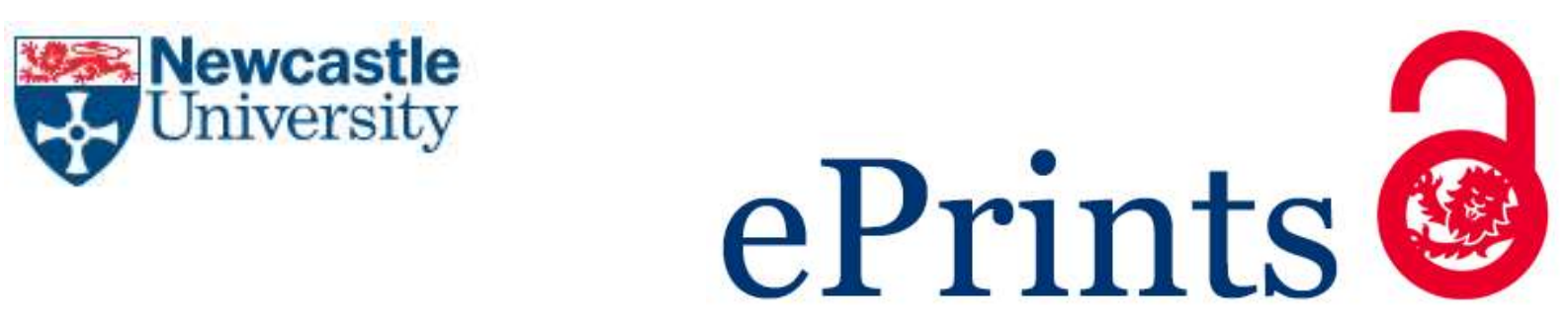

Durham J, Nixdorf DR. Healthcare pathway and biopsychosocial impact of persistent dentoalveolar pain disorder: a qualitative study. International Endodontic Journal 2014, 47(12), 1151-1159.

\title{
Copyright:
}

This is the peer reviewed version of the following article: Durham J, Nixdorf DR. Healthcare pathway and biopsychosocial impact of persistent dentoalveolar pain disorder: a qualitative study. International Endodontic Journal 2014, 47(12), 1151-1159., which has been published in final form at http://dx.doi.org/10.1111/iej.12263 This article may be used for non-commercial purposes in accordance with Wiley Terms and Conditions for Self-Archiving.

Date deposited:

$02 / 12 / 2015$

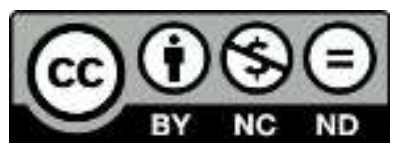

This work is licensed under a

Creative Commons Attribution-NonCommercial-NoDerivatives 4.0 International licence 


\section{Healthcare Pathway and Biopsychosocial Impact of Persistent Dentoalveolar Pain disorder (PDAP): A Qualitative Study}

Authors: Durham $\mathrm{J}^{1^{*}}$, Nixdorf $\mathrm{DR}^{2}$

Authors' affiliations:

1 - Institute for Health and Society and Centre for Oral Health Research, Newcastle University, UK

2- Division of TMD \& Orofacial Pain, School of Dentistry and Department of Neurology, Medical School, University of Minnesota, MN. Research Investigator, HealthPartners Institute for Education and Research, Bloomington, $\mathrm{MN}$.

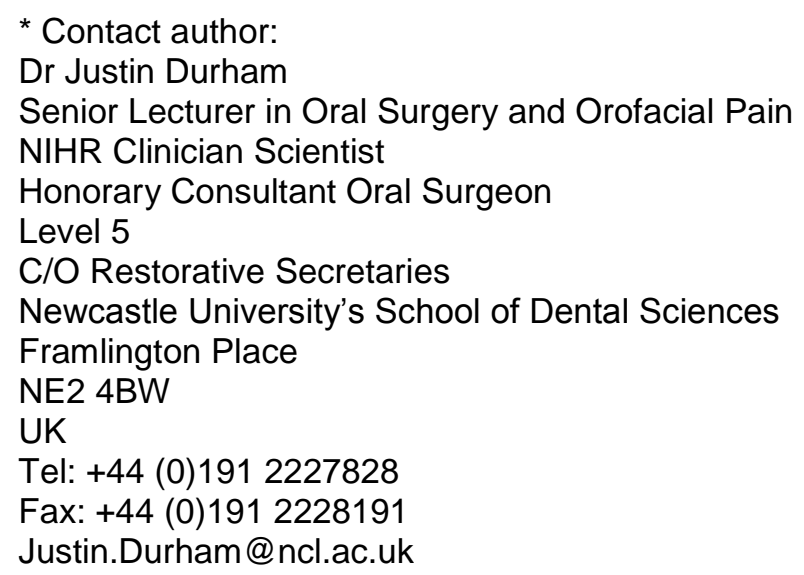

Running head: PDAP Healthcare pathway

\section{Key words:}

Persistent Dentoalveolar pain disorder (PDAP)

Healthcare pathway

Qualitative research

Biopsychosocial impact

Atypical odontalgia 


\section{Abstract}

Aim: To examine PDAP patients' reported experiences of the biopsychosocial impacts of the condition and its healthcare pathway.

Methods: Qualitative semi-structured interviews were conducted with a University-based cohort of PDAP patients. One interviewer used an openended, evolving, topic guide and all interviews were recorded and transcribed verbatim. Data collection and analysis continued until saturation $(n=20)$. The principles of the constant comparative method were followed and frameworks were used to help organise and analyse the data.

Results: PDAP exerts significant biopsychosocial impacts on the individual. These impacts occur across a wide variety of everyday activities including employment, personal relationships, and social activites. The conceptualisation and acceptance of PDAP is difficult for patients given the reinforcement of multiple ineffective dental treatments perceived as targeting the source of their pain.

Conclusion: There is an urgent need for earlier identification of PDAP cases in order to minimise the negative biopsychosocially effects of multiple dental interventions incorrectly applied to treat the symptom of pain. 


\section{Introduction}

Pain persistent following deafferenating dental procedures is a known outcome with an estimated frequency of $1.6 \%$ (Nixdorf \& Moana-Filho 2011). This type of pain has been reported in the literature since the 1750s (Hunter 1803) and has been recognised to exist under a variety of different names including atypical odontalgia, phantom tooth pain, and persistent idiopathic facial pain (Lascelles 1966, Harris 1974, Campbell et al. 1990, Graff-Radford \& Solberg 1992, Marbach 1996, Glennon et al. 2004, Baad-Hansen 2008). Each of these "pseudonyms" has slightly different defining criteria and this has led to ambiguity and confusion. An ontological approach has recently been used to reclassify persistent pain perceived within the dentoalveolar region as Persistent Dentoalveolar Pain disorder (PDAP) (Nixdorf et al. 2012). One aim of reclassification is to provide a foundation from which to build a greater understanding of this phenomenon so that descriptive assessments, such as conducted here, can appropriately be linked with existing and future research.

One way to increase clinical understanding of a condition is to critically examine the patient's perspectives of it (Pope \& Mays 1995), which can be a pivotal initial step in the process. The patients' perspectives on the manifestations of their condition provide data about the features of the condition so that clinicians may diagnose earlier with greater confidence (Durham et al. 2013). The qualitative approach used to examine patients' perspectives also helps to delineate the biopsychosocial impacts the condition exerts on the individual, which ultimately is one of the drivers behind seeking 
care. In patient-centred care these impacts should be the primary focus of clinicians when providing diagnoses and treatment (Turk et al. 2006).

Qualitative research has demonstrated in other (persistent) orofacial pain conditions, that both the condition and the healthcare pathway patients travel in search of treatment result in significant biopsychosocial impacts (Pau et al. 2000, Stoller et al. 2001, Wolf et al. 2006, Cohen et al. 2007, Wolf et al. 2008, Durham et al. 2011). These studies highlight orofacial pain's impacts on individuals' everyday lives and also explain the uncertainty it can cause and the concomitant anxiety this brings (Garro 1994, Garro et al. 1994, Pau et al. 2000, Anderson 2004, Durham et al. 2010). Some of the impacts that patients reported in these studies may be easily dealt with through simple adjustments in the logistics of healthcare pathways or by a slight alteration in clinician's behaviour, for example giving a provisional diagnosis as early as possible (Anderson \& Thomas 2003, Anderson 2004, Durham et al. 2010, Durham et al. 2011). Some of the impacts may also highlight areas of need that require research or instrument development. These impacts may not, however, be identified unless patients are able to discuss their experiences of their condition in-depth. A qualitative study was therefore undertaken with PDAP patients aiming to firstly identity a set of putative set of items for a screening instrument for PDAP, the results of which are now published (Durham et al. 2013), and secondly to examine the impacts of PDAP by giving patients the opportunity to discuss their experiences of their condition in-depth. This paper, therefore, examines the second aim of the qualitative study; the patients' reported experiences of the biopsychosocial impacts of PDAP and its 
healthcare pathway in order to provide a larger context in which to understand the disorder. 


\section{Methods}

This study was approved by the local institutional board review process (University of Minnesota, study number 1104S98353) and took a qualitative approach employing semi-structured interviews and an open-ended, evolving, topic guide in order to collect data on patient experiences of PDAP. This paper uses the same dataset arising from a cohort of patients interviewed for another published study (Durham et al. 2013).

Patients with PDAP were diagnosed using a combination of the currently published and accepted criteria for PDAP (Nixdorf et al. 2012), atypical odontalgia (Woda \& Pionchon 1999, Baad-Hansen 2008, List et al. 2008), idiopathic toothache (Melis et al. 2003), and persistent idiopathic facial pain (International Classification Headache 2004). The purposive, maximum variation, sample $(n=22)$ was taken from one University-based population of PDAP patients $(n=37)$ and aimed to sample a depth and a breadth of experiences of PDAP (Table 1). Of the twenty-two patients approached one declined in absentia over two scheduled interview appointments. All participants had been examined by one or more boarded experts in orofacial pain and had extensive multidisciplinary assessments, including imaging, to exclude any local, systemic, or distant pathology that could have been the source of the patient's pain.

After informed written consent, a single interviewer (JD) conducted all interviews either face-to-face or, due to the exigencies of travelling distance, 
by telephone. The interviewer was uninvolved in any of the patients' care. All interviews were digitally recorded, transcribed verbatim, and then crosschecked for accuracy. Data collection and analysis were concurrent and broadly followed the principles of the constant comparative method (Glaser 1965). An iterative and inductive analysis was undertaken coding the transcripts line-by-line and using frameworks (theme-by-theme and case-bycase) to organise the coded data (Ritchie \& Lewis 2003). Data collection and analysis continued until saturation, that is when no new themes or ideas emerged from on going analysis. In this study data saturation occurred after twenty interviews. In the presentation of the results we have provided quotations to help illustrate and support the points made. The patient details in parenthesis following the quotations can be cross-referenced to Table 1. 


\section{Results}

The patients' description of their pain has been covered in detail in a previous publication (Durham et al. 2013), but it is important to briefly outline the start of the patient's pain experience as it is the beginning of the patient's healthcare journey. The majority of those interviewed reported first experiencing the symptom of pain after a routine visit to, and treatment from, their dentist. When the patient reflected on their reason for attending their dentist for this treatment it was because in their terms they had a "toothache" (Pt 4), which they described using terms that would classically indicate either pain from a pulpal or periradicular origin.

"It was just like a...it was more than a ache, ya know, like a throbbing, and it just... It just wouldn't go away" (Pt 15)

Inevitably all participants then reported having an intervention from a dental professional aimed at the potential cause of the presumed odontogenic pain. These interventions were either endodontic or exodontic in nature. Post procedure all participants then described ongoing pain with descriptions falling broadly into two groups. One group reported that the post procedure pain was clearly different to the toothache prior to treatment, whereas the other group explained that it continued to be the same. Both groups identified the origin of their pain as either a very discreet area where the tooth once was, in the case of extractions, or the tooth itself, in the case of root canal treatment. It was this very definite, distinct, and well-defined "origin" to their pain that they articulated drove their belief that a dental (biomedical) intervention was needed to help resolve their symptom of pain. 
"I kept telling him, ya know, it hurts there, and ya know, and I get a toothache there ....and ah he couldn't do much about it... So I tell him, "Why don't you just pull it." (Pt 4)

"Well then she [attending dentist] says, okay... How bout, how bout if we do this. We'll [do] the surgery on that eye tooth, and clip the end of the root off...I said, yeah! Do it. No problem. Not even a hesitation.... Well she takes the end of the root off, and then that doesn't do nothing" (Pt 6)

In the early postoperative period patients reported clinicians undertook further treatments aimed at removing the localised perceived source of the pain. It is implicit in the patients' reports that they had a great deal of faith in the epistemological authority of dentistry and they underwent treatments without question, like "good trooper[s]" (Pt 18).

"I know, really was having a lot of tooth pain. I went to my [general] dentist, and he said, no, the tooth I thought it was had already had a root canal, so it must be the one in front of it...so he though well maybe we should do a root canal then on the one in front of that...And so we did a root canal...

[then after approximately 4-6 weeks of pain she was sent to see the endodontist]

And ah, let's see, the endodontist took a picture of the tooth and the root canal had gone straight down, and the nerves were curving off, and he said, well I can't fix...or maybe it was below that bone line or whatever. And he said, but you could see the oral surgeon and get the root shaved off. It is probably that tooth...so I made an appointment with the oral surgeon. So then I went in and saw him, and he said yes, he could do this root shaving thing, and that would take care of it, because then there wouldn't be any nerves to flare up

[then after approximately five months of pain]

Then the tooth was extracted.

[then after approximately six months of pain]

And then he [her general dentist] suggested that I see the endodontist" (Pt 2)

Eventually, because of the multiple failed treatments prior to an accurate diagnosis, some sufferers reported a realisation of the almost inevitable failure 
of these types of treatment. Some patients would still, however, undergo tooth-directed procedures to give themselves some hope.

"ya know, you deal with that pain so long that you're just hoping...you're hoping there is something wrong with that tooth. Ya know, hoping...even though you feel there's not, maybe that tooth being extracted will... will help correct the problem. But ...even when they went in to do the oral surgery and pull the tooth, and they numbed me up...I felt the sensation, so I had a feeling when they pulled it that it wasn't gonna do any good." (Pt 10)

Participants in this study reported having seen more than one healthcare speciality (minimum number 2, maximum number 8 ) including: general dentists, primary care physicians, endodontists, oral surgeons, neurology, ear nose and throat surgeons, pain psychologists, periodontists, oral medicine specialists, physical therapists, and orofacial pain practitioners. They explained that generally this was, in the first instance, due to onwards referral from the last care provider who had either exhausted all possibilities with them or felt an alternative diagnosis might be possible. Some, however, reported the desperation of the continuing pain, "I mean, I was willing to do pretty dramatic things to get rid of that pain" (Pt 9), and their search for answers, which could lead them to investigate other specialities. This they explained could lead them to both recognised and unrecognised authorities in the area.

"I went to one guy, or didn't go to a guy...Now l'm forgetting his name. But I was, again, doing some research and there was um... a guy in [locations] who specialized in where there were pockets ...there's some term for this. Where he would go in and these special kind of $x$-rays would show pockets....And I thought, okay, nobody's finding anything... what the heck, ya know, what have I go to lose? And I was so close to going to [location] to have this guy check me out. And I thought, ya know what, I'm gonna check this guy out. So, I did, and it turns out that he's got 
major lawsuits against him, and his license is being threatened, and I'm like, ya know, maybe I'm not gonna go to that guy." (Pt 17)

Patients also reported examining, and in some instances undergoing,

alternative therapies including: chiropractic care and acupuncture.

Once an accurate diagnosis of PDAP was given, individuals' accounts highlight the struggle they faced to understand and accept the nature of the problem. This difficulty in acceptance related to the almost intangible nature of the problem and conceptualising that the nerves that involved in the transmission of pain could not be repaired in some form or another.

"Because, you can't see it [the neuropathic pain], and you can't do a test or a CT scan or an MRI and show that something is there. Um...so it's frustrating to find out what the cause is." (Pt 20)

"Well it's hard to believe when... when you're a patient, and you go in and ya know, they do those tests and things, and he really did a super job. And then um...ah...he's says well, ya know, it looks to me like it's trigeminal neuroptic [sic, neuropathic] pain. Ya know you still wonder...Did they miss something?" (Pt 10)

"That [accepting of the pain] has just been recent. That has been within the last couple of years. The beginning was more a denial kind of thing. I wanted it gone. I wanted it handled, and so I am sure that is where all of the multiple procedures came in. I was looking for something [emphasis from patient] that was eventually going to stop this pain" (Pt 1)

The persistent nature of the pain had a tiring effect, "it takes away from the horsepower that I need" (Pt 5), and there were few areas of life that it did not impact upon. The majority of the biopsychosocial impacts reported were interrelated. 
"It [the ongoing pain] affects your sex life. It affects everything, because, ya know, you're not in the mood to work. You're not in the mood to be intimate. Ah, you're not even in the mood to sit in front of the TV, because if you...TV is too passive, and you need something a little more interactive to help take your mind off it." (Pt 2)

"I was really depressed about it [the ongoing pain], and especially when doctors couldn't figure out, ya know, what was going on. And I didn't do a whole lot socially" (Pt 15)

"I only missed like one day of work, but it was like that one day every other week was about as much as I could take...the job that I do requires that I do a lot of detail work. And I find myself sending off e-mails that had words missing and, ya know, just made no sense... I couldn't do anything. I couldn't eat. I couldn't sleep... I lost weight...there was things that I should've been doing, but I just wasn't...my parents are elderly. I just didn't visit them. I didn't call em...I was supposed to be doing other things... just didn't do 'em" (Pt 8)

Patients within the sample did not consistently report stigmatisation and discreditation (Goffman 1963) of their persisting pain by family and friends. They seemed to report receiving social support for their problem, but there were sporadic reports from individual patients that some health professionals felt their complaint was the result of another problem. The other problems implicated would seem to be stigmatising conditions from the patient's perspective.

"In fact, the one dentist in my husband's office that I went to...I didn't go to her for long, because she was...ya know...well, at any rate. She very specifically said to me, "This is all in your head. You need to learn to relax." [how did that make you feel?] it made me mad actually.... always knew it was real." (Pt 9)

"He [the attending health professional] thought I was a pill junky, I think because he didn't know me...he really did. My husband had to talk to him [about her not being a pill junky]. The pain medication, because my husband could see that it was real." (Pt 2)

Despite multiple failed treatments the continued social support may have been related to a strong patient (and societal) illness representation that local 
tooth-related pathology was causing the pain. This suggests that professionals just hadn't found the problem as yet; they were medically explained symptoms and so readily accepted and easy to build an illness representation around (Goodman et al. 2005).

"Fortunately, I have a very nice, understanding husband, because sometimes I get home from work and I just lay on the couch and try to rest my face. And, ya know, he's just so understanding and sympathetic, cuz ya know, if I had a jerk for a husband, he might just be mean" (Pt 12)

"I think they [his friends] know that I know what l'm talking about, ya know, and I'm not faking what's going on. I'm telling em what I know, and when they do tests and things, they [the health professionals] get the kind of reaction they might, ya know, expect from any patient that has a problem" (Pt 7)

Self-taught management strategies for the on going pain varied enormously.

The three most common pain reducing strategies that were reportedly employed were: decreasing their amount of talking, applying ice to the area of pain, and chewing gum.
"So, watch the talking...If it got to be too much, ice always help, so I would suck ice, or eat something cold. So that would kind of deaden that area to try to tone it down..." (Pt 1)
"I was, still sort of am...a proponent of chewing gum. Ya know, I chewed it a long time ago when I stopped smoking. And then when my teeth became bad, l'd chew gum to relieve the pain in my mouth. And that sort of took the pain away" (Pt 7)

Those who had tried systemic medications for their pain explained that it was of some benefit, but that sometimes the side effects outweighed the benefits. As a result some reported having stopped taking the medication(s) because of its high level of impact on their everyday lives.

"I don't really want to take medication, cuz medication ah...ya know, either really affects me a funny way, or I can't function in my day-to-day. And I would rather have, knowing this familiar 
pain, and go along with my life then taking medication that is compromising who I am or what I can do" (Pt 20)

"The pain has gone down, so I can still function now in my dayto-day. It took me a couple of months, I think for the...for me to get used to all the side effects and maybe the medicine to stabilize cuz I still had the ups and downs of the pain" (Pt 8)

The recurring feeling about management of PDAP reported was that this pain condition was something that was going to last forever and there was little further that they could do other than live with it, "I'm not gonna get rid of it. It's like Samsonite luggage. I have it forever" (Pt 16). 


\section{Discussion}

There is a clear description of a localised pain that persists despite treatments, which although reported as a low intensity, exerts significant biopsychosocial impacts. Given the nature of the biopsychosocial impacts reported it is likely that oral health related quality of life measures (OHRQOL) would capture some, if not all, of these impacts and may represent a useful mechanism to objectively measure the impact of this pain, and is a topic that remains unexplored.

Seemingly given the very localised nature and low intensity of PDAP the sample tended not to reconstruct the pain as anything other than a tooth related pain. This is in direct contrast to qualitative studies conducted with sufferers of Temporomandibular Disorders (TMDs) who reconstructed their pain, prior to diagnosis, as something sinister or serious (Durham et al. 2010, Durham et al. 2011). The very localised nature of the pain may also have been one of factors that prevented felt or enacted stigma (Goffman 1963) from occurring in the majority of the sample. The pain was easier to conceptualise and "biomedically diagnose" for clinicians than a pain that referred or radiated to other areas such as TMDs (Durham et al. 2010, Durham et al. 2011).

Discreditation of their complaint was reported by some of the sample and this tended to be in those who had returned multiple times to the same clinician. This repeat attendance potentially called into question the clinician's 
diagnostic ability and management of the pain. As well, it may be that this affront resulted in clinicians taking a defensive stance based on the "objectivity" of the somewhat blunt diagnostic tests/tools dentistry possesses for this type of pain (Hyman \& Cohen 1984, Tidwell et al. 1999, Jafarzadeh \& Abbott 2010a, Jafarzadeh \& Abbott 2010b). The sample's illness representation of the problem was that, given its initial presentation and localised nature, it was odontogenic and this seemingly both drove their repeated attendance, and reinforced their and the professionals' perception that further dental treatment was required.

Disease conviction, a slightly broader construct, has been shown to be high in patients with persistent orofacial pain previously (Allerbring \& Haegerstam 1995, Pigg et al. 2013). In the first instance, however, our cohort had a rationale as to why they felt the pain had a somatic origin. It is conceivable that from this viewpoint, a lay diagnosis of odontogenic pain, they may actually even be conditioned by exposure to multiple ineffectual treatments to more firmly hold the belief that pain means damage.

Eventually the repeated attendances, multiple failed treatments, or the receipt of a correct diagnosis called into question the epistemological authority of the healthcare professionals. Given that most patients reported believing the tooth (socket) was the cause of the problem receiving a correct diagnosis challenged their illness representation. Within the data it would appear that this realisation of a misdiagnosis and the subsequent explanation of the 
somewhat intangible, idiopathic, nature of PDAP is a difficult point in the patient's journey through care. Not only is it difficult to comprehend and reconceptualise their problem, repeated tooth-centric treatments have left the individual potentially less responsive to other attempts at management through a variety of biopsychosocial changes (Hunter 1803, Glaser 1928, McElin \& Horton 1947, Marbach \& Raphael 2000, Israel et al. 2003, Fine 2011).

There are limitations to our dataset in that we used a purposive sample from a University cohort and therefore by its very nature our sample is not representative. Our sample does, however, explore a depth and breadth of individuals' experiences in a sample of patients with a varying presentation of PDAP (i.e. anatomic location, pain intensity, pain quality, aggravating factors, alleviating factors). Apparent in our data is that patients were clearly seeking and receiving large amounts of healthcare, which consumes considerable resources to obtain diagnosis and "treatment" of PDAP.

Our sample clearly experienced repeated interventions targeting presumed odontogenic pain and this is not uncommon in persistent orofacial pain (Allerbring \& Haegerstam 1995, Marbach \& Raphael 2000, Oshima et al. 2009, Pigg et al. 2013). Given emerging evidence in PDAP and other persistent pain conditions these repeated interventions may have exerted biopsychosocially damaging effects through central sensitisation, creation of helplessness, operant conditioning in pain beliefs, or the creation of a liminal state between 
health and illness (Madland \& Feinmann 2001, Flor et al. 2002, List et al. 2007, Fernandez-de-las-Penas et al. 2009, Durham et al. 2010, Anderson et al. 2011, Cady et al. 2011, Lorduy et al. 2013). There is an urgent need for more expedient mechanisms by which to identify PDAP earlier either through new screening instrumentation, determination of predictive factors, identification of biomarkers, improved diagnostic imaging techniques, or revised logistical arrangements for suspicious post-procedure symptoms.

Earlier identification of PDAP may be one way to help reduce the reported biopsychosocial impacts of the healthcare pathway by decreasing the number care providers seen, procedures experienced, and costs incurred. It is also conceivable, but not proven, that earlier identification will help improve the efficacy of treatment since treatments may be more effective when applied earlier with the disorders, before increased "centralization" of their pain occurs. 


\section{Conclusion}

PDAP produces significant biopsychosocial impacts, some of which may be influenced by the healthcare pathway the patient experiences. Research focusing on understanding this pathway is needed to minimize the impact PDAP has on individual patients. 


\section{Acknowledgements}

The authors would like to acknowledge the patients who participated in this study and Drs. Cory Herman and Mariona Mulet for the help they provided in recruiting patients to the study. We would also like to acknowledge $\mathrm{Dr}$ Catherine Exley for her independent review of the data involved in the study. We acknowledge and thank the University of Minnesota for awarding a Lasby Fellowship to Dr. Durham in order to conduct this study and Linda BergstedtCleveland for administering the study.

Dr. Durham is funded by a NIHR Clinician Scientist award (NIHR-CS-011003). The views expressed in this publication are those of the author(s) and not necessarily those of the NHS, the National Institute for Health Research, or the Department of Health in the United Kingdom. 


\section{References}

Allerbring, M \& Haegerstam, G (1995) Invasive dental treatment, pain reports, and disease conviction in chronic facial pain patients. A retrospective study. Acta Odontologica Scandinavica 53, 41-3.

Anderson, GC, John, MT, Ohrbach, R et al. (2011) Influence of headache frequency on clinical signs and symptoms of TMD in subjects with temple headache and TMD pain. Pain 152, 765-71.

Anderson, R (2004) Patient expectations of emergency dental services: a qualitative interview study. British Dental Journal 197, 331-4; discussion 323.

Anderson, R \& Thomas, DW (2003) 'Toothache stories': a qualitative investigation of why and how people seek emergency dental care. Community Dental Health 20, 106-11.

Baad-Hansen, L (2008) Atypical odontalgia - pathophysiology and clinical management. Journal of Oral Rehabilitation 35, 1-11.

Cady, RJ, Glenn, JR, Smith, KM \& Durham, PL (2011) Calcitonin gene-related peptide promotes cellular changes in trigeminal neurons and glia implicated in peripheral and central sensitization. Molecular Pain 7, 94.

Campbell, RL, Parks, KW \& Dodds, RN (1990) Chronic facial pain associated with endodontic therapy. Oral Surgery, Oral Medicine, Oral Pathology 69, 287-90. 
Cohen, LA, Harris, SL, Bonito, AJ et al. (2007) Coping with toothache pain: a qualitative study of low-income persons and minorities. Journal of Public Health Dentistry 67, 28-35.

Durham, J, Exley, CE, John, MT \& Nixdorf, DR (2013) Persistent dentoalveolar pain: the patient's experience. Journal of Orofacial Pain 27, 613.

Durham, J, Steele, J, Moufti, MA, Wassell, R, Robinson, P \& Exley, C (2011) Temporomandibular disorder patients' journey through care. Community Dentistry Oral Epidemiology 39, 532-41.

Durham, J, Steele, JG, Wassell, RW \& Exley, C (2010) Living with uncertainty: temporomandibular disorders. Journal of Dental Research 89, 827-30.

Fernandez-de-las-Penas, C, Galan-del-Rio, F, Fernandez-Carnero, J, Pesquera, J, Arendt-Nielsen, L \& Svensson, P (2009) Bilateral widespread mechanical pain sensitivity in women with myofascial temporomandibular disorder: evidence of impairment in central nociceptive processing. Journal of Pain 10, 1170-8.

Fine, PG (2011) Long-term consequences of chronic pain: mounting evidence for pain as a neurological disease and parallels with other chronic disease states. Pain Medicine 12, 996-1004.

Flor, H, Knost, B \& Birbaumer, N (2002) The role of operant conditioning in chronic pain: an experimental investigation. Pain 95, 111-8. 
Garro, LC (1994) Narrative representations of chronic illness experience: cultural models of illness, mind, and body in stories concerning the temporomandibular joint (TMJ). Social Science \& Medicine 38, 775-88.

Garro, LC, Stephenson, KA \& Good, BJ (1994) Chronic illness of the temporomandibular joints as experienced by support-group members. Journal of General Internal Medicine 9, 372-8.

Glaser, BG (1965) The constant comparative method of qualitative analysis. Social Problems 12, 436-45.

Glaser, MA (1928) Atypical neuralgia, so called: A critical analysis of one hundred and forty-three cases. Archives of Neurology \& Psychology 20, 53758.

Glennon, JP, Ng, YL, Setchell, DJ \& Gulabivala, K (2004) Prevalence of and factors affecting postpreparation pain in patients undergoing two-visit root canal treatment. International Endodontic Journal 37, 29-37.

Goffman, E. (1963) Stigma. Notes on the Management of Spoiled Identity. Prentice-Hall, New Jersey.

Goodman, D, Morrissey, S, Graham, D \& Bossingham, D (2005) Illness representations of systemic lupus erythematosus. Qualitative Health Research 15, 606-19.

Graff-Radford, SB \& Solberg, WK (1992) Atypical Odontalgia. Journal of Craniomandibular Disorders 6, 260-5. 
Harris, M (1974) Psychogenic aspects of facial pain. British Dental Journal 136, 199-202.

Hunter, J. (1803) The natural history of human teeth. R.Harwicke, London.

Hyman, JJ \& Cohen, ME (1984) The predictive value of endodontic diagnostic tests. Oral Surgery, Oral Medicine, Oral Pathology 58, 343-6.

Israel, HA, Ward, JD, Horrell, B \& Scrivani, SJ (2003) Oral and maxillofacial surgery in patients with chronic orofacial pain. Journal of Oral Maxillofacial Surgery 61, 662-7.

Jafarzadeh, H \& Abbott, PV (2010a) Review of pulp sensibility tests. Part II: electric pulp tests and test cavities. International Endodontic Journal 43, 94558.

Jafarzadeh, H \& Abbott, PV (2010b) Review of pulp sensibility tests. Part I: general information and thermal tests. International Endodontic Journal 43, 738-62.

Lascelles, RG (1966) Atypical facial pain and depression. British Journal Psychiatry 112, 651-9.

List, T, Leijon, G, Helkimo, M, Oster, A, Dworkin, SF \& Svensson, P (2007) Clinical findings and psychosocial factors in patients with atypical odontalgia: a case-control study. Journal of Orofacial Pain 21, 89-98.

List, T, Leijon, G \& Svensson, P (2008) Somatosensory abnormalities in atypical odontalgia: A case-control study. Pain 139, 333-41. 
Lorduy, KM, Liegey-Dougall, A, Haggard, R, Sanders, CN \& Gatchel, RJ (2013) The Prevalence of Comorbid Symptoms of Central Sensitization Syndrome Among Three Different Groups of Temporomandibular Disorder Patients. Pain Practice In press

Madland, G \& Feinmann, C (2001) Chronic facial pain: a multidisciplinary problem. Journal of Neurology, Neurosurgery, \& Psychiatry 71, 716-9.

Marbach, J \& Raphael, KG (2000) Phantom tooth pain: a new look at an old dilemma. Pain Medicine 1, 68.

Marbach, JJ (1996) Phantom Tooth Pain: Differential Diagnosis and Treatment. Journal of the Massachusetts Dental Society 44, 14-8.

McElin, TW \& Horton, BT (1947) Atypical face pain; a statistical consideration of 66 cases. Annals of Internal Medicine 27, 749-68.

Melis, M, Lobo, SL, Ceneviz, C et al. (2003) Atypical odontalgia: a review of the literature. Headache 43, 1060-74.

Nixdorf, D \& Moana-Filho, E (2011) Persistent Dento-Alveolar Pain Disorder (PDAP): Working towards a Better Understanding Reviews in Pain. 5, 18-27.

Nixdorf, DR, Drangsholt, MT, Ettlin, DA et al. (2012) Classifying orofacial pains: a new proposal of taxonomy based on ontology Journal of Oral Rehabilitation. 39, 161-9.

Oshima, K, Ishii, T, Ogura, Y, Aoyama, Y \& Katsuumi, I (2009) Clinical investigation of patients who develop neuropathic tooth pain after endodontic procedures. Journal of Endodontics 35, 958-61. 
Pau, AK, Croucher, R \& Marcenes, W (2000) Perceived inability to cope and care-seeking in patients with toothache: a qualitative study. British Dental Journal 189, 503-6.

Pigg, M, Svensson, P, Drangsholt, M \& List, T (2013) Seven-Year Follow-up of Patients Diagnosed with Atypical Odontalgia: A Prospective Study. Journal of Orofacial Pain 27, 151-64.

Pope, C \& Mays, N (1995) Reaching the parts other methods cannot reach: an introduction to qualitative methods in health and health services research. British Medical Journal 311, 42-5.

Ritchie, J \& Lewis, J. (2003) Qualitative research practice : A guide for social science students and researchers. Sage, London.

Stoller, EP, Gilbert, GH, Pyle, MA \& Duncan, RP (2001) Coping with tooth pain: a qualitative study of lay management strategies and professional consultation. Special Care Dentist 21, 208-15.

The International Classification of Headache Disorders: 2nd edition (2004). Cephalalgia 24 Suppl 1, 9-160.

Tidwell, E, Witherspoon, DE, Gutmann, JL, Vreeland, DL \& Sweet, PM (1999) Thermal sensitivity of endodontically treated teeth. International Endodontic Journal 32, 138-45.

Turk, DC, Dworkin, RH, Burke, LB et al. (2006) Developing patient-reported outcome measures for pain clinical trials: IMMPACT recommendations. Pain 125, 208-15. 
Woda, A \& Pionchon, P (1999) A unified concept of idiopathic orofacial pain: clinical features. Journal of Orofacial Pain 13, 172-84.

Wolf, E, Birgerstam, P, Nilner, M \& Petersson, K (2006) Patients' experiences of consultations for nonspecific chronic orofacial pain: A phenomenological study. Journal of Orofacial Pain 20, 226-33.

Wolf, E, Birgerstam, P, Nilner, M \& Petersson, K (2008) Nonspecific chronic orofacial pain: studying patient experiences and perspectives with a qualitative approach. Journal of Orofacial Pain 22, 349-58. 


\section{Tables}

Table 1 - Sample details

\begin{tabular}{|l|l|l|l|l|l|l|}
\hline $\begin{array}{l}\text { Study } \\
\text { id. }\end{array}$ & Gender & Age & Tooth & $\begin{array}{l}\text { Jaw } \\
\text { location }\end{array}$ & $\begin{array}{l}\text { Duration } \\
\text { of } \\
\text { pain/years }\end{array}$ & Tooth status \\
\hline 1 & Female & 49 & Premolars & $\begin{array}{l}\text { Mandible } \\
\text { and maxilla }\end{array}$ & 11 & $\begin{array}{l}\text { Mandibular removed. } \\
\text { Maxillary in situ }\end{array}$ \\
\hline & & & & & & \\
\hline 2 & Female & 60 & Molar & Mandible & 2 & Removed \\
\hline 3 & Female & 55 & Molar & Maxilla & 9 & Removed \\
\hline 4 & Female & 72 & Molar & Maxilla & 9 & In situ \\
\hline 5 & Male & 43 & Premolar & Maxilla & 10 & In situ \\
\hline 6 & Male & 66 & Canine & Maxilla & 5 & In situ \\
\hline 7 & Male & 68 & Molar & Maxilla & 3 & In situ \\
\hline 8 & Female & 55 & Molar & Maxilla & 1 & In situ \\
\hline 9 & Female & 61 & Molars & $\begin{array}{l}\text { Mandible } \\
\text { and maxilla }\end{array}$ & 10 & Maxillary removed \\
Mandibular in situ
\end{tabular}

